\title{
An introductory statistics class and examination using SPSS/PC
}

\author{
ELLEN F, ROSEN and BROOKE FEENEY \\ College of William and Mary, Williamsburg, Virginia \\ and \\ LINDA C. PETTY \\ Hampton University, Hampton, Virginia
}

\begin{abstract}
SPSS/PC was integrated into lecture and an examination in introductory statistics. Students were given an anonymous questionnaire after a traditional examination and again after an examination with SPSS/PC. They wanted more theory and derivation and were ambivalent about SPSS/PC in lecture. The computer test decreased computational error fears. Students preferred the more realistic questions which the computer permitted. Test performance was not significantly different. The results suggest that statistical packages should be used in later courses rather than in introductory statistics.
\end{abstract}

Students are required to learn to use computer software packages for statistical analysis in many introductory statistics courses. Often the use of such software is incorporated within the textbook. Computer software training and practice, however, are usually relegated to homework and to the laboratory portion of the class (see, e.g., Tromater, 1985; Vasu, Vasu, \& Babcock, 1985; Ware \& Chastain, 1989). Student achievement in this learning task is evaluated, at best, with the use of outside projects such as homework assignments and, at worst, by means of questions on examinations, such as the following:

Correct the error in the following SPSS/PC + commands:
a. crosstabs rowvar by colvar
b. cross zodiac with life
c. crosstabs zodizc by life for marital

(Norusis, 1991b). With the increasing availability of PCs in the classroom, however, it has become feasible not only to incorporate the use of software during classroom statistics lectures, but also to allow students to use the software on their examinations, taking away the necessity for rote learning of statistical programming commands, memorization of the arbitrary rules of the command language, memorization of formulae, and laborious, error-laden, hand calculation of answers. The present study was performed to assess student perceptions of this enhancement, since most prior discussion has been focused on the perceptions of the instructors.

\section{METHOD}

\section{Subjects}

The subjects were 25 undergraduate psychology students enrolled in an introductory psychology statistics course, required of all majors, which was taught by the first author with the assistance

Correspondence should be addressed to E. F. Rosen, Department of Psychology, College of William and Mary, Williamsburg, VA 23187 (e-mail: efrose@mail.wm.edu). of the second. The instructors used SPSS/PC (Version 4.01) in class; the computer, on a cart, was connected to a TV monitor. The students were taught to use the package through its menu system so that they did not have to memorize the commands. Witte (1993) and Norusis (1991a) were the textbooks for the course. SPSS/PC was available for student use on the networked computers in the PC laboratories on campus. For most of the students, this class was their first psychology course beyond introductory psychology.

\section{Procedure}

Two examinations were given, separated by a few weeks. The first was a traditional in-class examination with two parts-closed book and open book. The first examination was given in the classroom and the second in the PC Laboratory, where the laboratory sessions of the class were held weekly. Since this room has only about 17 PCs, the second examination was given during the regular weekly laboratory session for which the class was split in half. After the second examination, the students were requested to fill out an anonymous questionnaire. Because the questionnaire was anonymous, the students' responses could not be matched with their grades. The questionnaire consisted of a series of questions asking the students to compare the two examinations, keeping in mind that for the open-book part of the first examination they had no computer or SPSS available, whereas for the second examination they used a computer for the open-book portion. They answered seven questions about the impact of computer availability using a Likerttype scale. Then they were asked four open-ended questions that gave them an opportunity to make comments about the same issues. Part 2 of the questionnaire comprised three questions about the type of items that were on the tests, and Part 3 comprised four questions about the use of SPSS in lecture.

\section{RESULTS}

Scores on the two examinations were calculated as percentages of correct answers. Scores on the two examinations did not differ significantly $[M=70.7, S D=11.8$, and $M=72.8, S D=15.7$, for the first and second examinations, respectively; $t(24)=-.75, p>.05$ ].

Twenty-two of the 25 students in the class returned the questionnaires. The questions were worded in such a way that students were asked to make a comparison between 
the first examination (no computer and no SPSS/PC available) and the second examination (computer and SPSS/PC available). Table 1 summarizes these data.

Students reported that, on the average, knowing they were going to be able to use the computer did not decrease their anxiety, although they had predicted that it would. Surprisingly, they were ambivalent about the helpfulness of the computer, but they did report a better liking for the way the second test was given. They were, on the average, ambivalent about which test permitted them to show their knowledge better, and about whether the computer provided them with any additional information. On the average, the students found that the presence of the computers added some confusion to the test and that the computer room itself was somewhat distracting. However, on the average, they preferred the second test and felt that it gave them a better opportunity to display their knowledge because of the difference in the way the questions were worded (less theoretical, more specifically aimed toward computer analysis).

With respect to the class as a whole, the students, on the average, indicated a weak belief that there was too much emphasis on computers in the class, and they were ambivalent about whether the use of the computer and SPSS/PC in class was helpful. They wanted more calculations done in class by hand using a calculator, and there was a tendency to want more theory and derivation in class lectures.

The open-ended questions were analyzed by grouping similar responses together. Frequencies of the various comments are summarized in Table 2.

\section{DISCUSSION}

Had the content and context of each examination been the same, and if a counterbalanced procedure could have been used, the conclusions drawn from this study would represent more than speculation. Given this caveat, these

Table 1

Some Descriptive Statistics From the Survey

\begin{tabular}{llllll}
\hline \multicolumn{1}{c}{ Question } & \multicolumn{1}{c}{ Coding } & $M$ & $S D$ & Median & Mode \\
\hline Part 1. Computer availability & & & & \\
Felt less anxious & $1=$ less & 4.0 & 2.0 & 4.0 & 3.0 \\
How helpful & $1=$ helpful & 4.0 & 2.1 & 3.5 & 2.0 \\
Prefer test & $1=$ first & 4.0 & 2.1 & 6.0 & 7.0 \\
Showed knowledge & $1=$ first & 3.9 & 2.1 & 4.0 & 1.0 \\
Made confusing & $1=$ less & 5.1 & 1.7 & 5.0 & 4.0 \\
Information & $1=$ too much & 3.6 & 1.5 & 4.0 & 4.0 \\
Distractions & $1=$ too many & 3.1 & 1.0 & 3.0 & 4.0 \\
Part 2. Examination questions & & & & \\
Prefer test & $1=$ first & 4.6 & 2.3 & 6.0 & 6.0 \\
Show knowledge & $1=$ first & 4.9 & 2.0 & 5.5 & 6.0 \\
No. items on & & & & & \\
Test2 & $1=$ too many & 3.5 & 0.9 & 4.0 & 4.0 \\
Part 3. Course & & & & & \\
Computer emphasis & $1=$ too much & 3.5 & 1.9 & 3.0 & 4.0 \\
Computer in class & $1=$ helpful & 4.3 & 2.3 & 4.5 & 7.0 \\
Hand computation & $1=$ much more & 3.2 & 1.8 & 3.0 & 1.0 \\
Theory/derivation & $1=$ more & 3.5 & 2.3 & 2.0 & 2.0 \\
\hline
\end{tabular}

Table 2

Responses $(N=22)$ to Open-Ended Questions About the Effect of Having a PC and SPSS Available During the Examination

\begin{tabular}{clc}
\hline \multicolumn{1}{c}{ Question } & \multicolumn{1}{c}{ Response Category Given } & Frequency \\
\hline How I studied & Used workbook more & 1 \\
& Practiced SPSS commands & 7 \\
& Studied formulas less & 5 \\
& Did not memorize commands & 4 \\
& Studied appropriate test selection & 1 \\
& Studied less theory/concepts & 2 \\
& Studied more concepts & 4 \\
Exam-taking strategy & No difference & 6 \\
& More time on closed book & 3 \\
& More time on concepts & 1 \\
& More time on open book & 1 \\
& Difference but not specified & 5 \\
& No difference & 12
\end{tabular}

Changed my confidence about my ability to do well on exam

Increased my confidence because...

I worked faster

I did not make arithmetic errors

I had increased knowledge of SPSS

SPSS tells you when you are wrong

Increased but not specified

Decreased my confidence because. .

I did not know enough SPSS

Computer anxiety

I could not demonstrate statistics knowledge

Decreased but not specified

Confidence did not change

Changed aspects of the test situation for me

In a positive way

Decreased emphasis on arithmetic 2

Helped recall 2

Faster

Less formal

Positive but not specified

In a negative way

Rushed

Not enough experience with SPSS

Technical problems with computer

Computer anxiety

Negative but not specified

Did not change

\begin{tabular}{l}
1 \\
1 \\
1 \\
7 \\
\\
5 \\
2 \\
2 \\
1 \\
2 \\
\\
\\
2 \\
2 \\
3 \\
1 \\
2 \\
2 \\
5 \\
3 \\
1 \\
1 \\
3 \\
\hline
\end{tabular}

data suggest that students at the introductory psychological statistics course level do not yet appreciate how helpful the existence of standard computer data analysis packages such as SPSS/PC can be. They did not feel that they had an adequate opportunity to really learn SPSS. They requested that more time be devoted to concepts, theories, and derivations in class. For most of the students, computer availability during the examination was not helpful beyond some simple benefits such as not having to worry about arithmetic errors. Thus, students should probably be introduced to computer packages such as these later in their training. This is the approach taken by Tromater (1985). He introduced a second course in statistics to meet this need. At William and Mary, introductory statistics comes right after introductory psychology and before experimental methods. Because of this order, delaying the instruction in the use of the statistical package until experimental methods might be better. In the experimental methods course, students have a personal need for data analysis to deal with their own data rather than constructed 
data sets. Need-driven computer learning seems to be the most effective motivator with adult learners.

It would be better to use the computer for tutorials on statistics, or to run a computer package that allows students to explore statistical concepts while helping them prevent arithmetic errors. Most such aids seem to be aimed at helping students choose the correct statistics (the "selection" problem). Marcoulides (1990) reports the successful use of such computer programs as adjuncts to classroom lectures. He gave students either computer-assisted instruction (CAI) programs, which described the statistical procedure and gave a list of key concepts and some review questions with feedback, or an expert system program, which selected the proper statistical procedure by interviewing the student and then calculated the statistic. Both improved student performance on examinations over that of students who only had the material presented in lecture. But it was not clear whether just the extra assignments produced the difference in achievement. Varnhagen and Zumbo (1990) used a design in which the control group and the CAI groups had, equivalently, no computer laboratory experience. They found no differential effects on performance, but those who had the CAI experience were much more positive about the laboratory experience. They recommend CAI computer experiences for introductory statistics simply because of this positive effect on attitude. According to Bloom (1971), developing a positive affect is an important part of the mastery process.

\section{REFERENCES}

Bloom, R. S. (1971). Affective consequences of school achievement. In J. H. Block (Ed.), Mastery learning (pp. 12-29). New York: Holt, Rinehart \& Winston.

MARCOUlides, G. A. (1990). Improving learner performance with computer based programs. Journal of Educational Computing Research, 6, $147-155$.

NorusIs, M. J. (1991a). The SPSS guide to data analysis for SPSS/PC+ (2nd ed.). Chicago: SPSS Inc.

Norusis, M. J. (1991b). SPSS/PC+ Studentware Plus instructor's manual. Chicago: SPSS Inc.

Tromater, L. J. (1985). Teaching a course in computer-assisted statistical analysis. Teaching of Psychology, 12, 225-226.

VARnhaGen, C. K., \& Zumbro, B. D. (1990). CAI as an adjunct to teaching introductory statistics: Affect mediates learning. Journal of Educational Computing Research, 6, 29-40.

VASU, E. S., Vasu, M. L., \& BabCock, S. F. (1985). Teaching the elaboration model using computer simulation. Simulation \& Games, 16, 33-48.

Ware, M. E., \& Chastain, J. D. (1989). Computer-assisted statistical analysis: A teaching innovation? Teaching of Psychology, 16, 222-226.

WrTte, R. S. (1993). Statistics (4th ed.). Orlando, FL: Harcourt, Brace, Jovanovich. 